\title{
The Application of Thermosensitive Nanocarriers in Controlled Drug Delivery
}

\author{
Pengyu Shao, ${ }^{1}$ Bochu Wang, ${ }^{1,2}$ Yazhou Wang, ${ }^{1}$ Jun Li, ${ }^{1}$ and Yiqiong Zhang ${ }^{1}$ \\ ${ }^{1}$ College of Bioengineering, Chongqing University, Chongqing 400044, China \\ ${ }^{2}$ Key Laboratory of Biorheological Science and Technology, Ministry of Education, College of Bioengineering, \\ Chongqing University, Chongqing 400044, China
}

Correspondence should be addressed to Bochu Wang, wangbc2000@126.com

Received 14 October 2010; Revised 1 February 2011; Accepted 3 March 2011

Academic Editor: Jun Li

Copyright (c) 2011 Pengyu Shao et al. This is an open access article distributed under the Creative Commons Attribution License, which permits unrestricted use, distribution, and reproduction in any medium, provided the original work is properly cited.

\begin{abstract}
Thermosensitive nanocarriers as the "smart" drug delivery systems have shown tremendous promise in the field of controlled drug delivery due to their special property. Thermosensitive nanocarriers with long circulation properties can accumulate in the pathological sites by enhanced permeability and retention (EPR) effect or attach targeting ligands to the surface of the nanocarriers, and the drug release rates of these pharmaceutical nanocarriers can be adjusted in response to thermal variability of the environment. In this paper, we first discuss the classification of thermosensitive polymer according to their functional properties in thermosensitive nanocarriers. On the basis of this, our main purposes are focused on reviewing the characteristics of various thermosensitive nanocarriers including the strategies for their functionalization, thermosensitive behavior, or site-specific targeting. Furthermore, the paper discusses the current and future trends of the thermosensitive nanocarriers in controlled drug delivery.
\end{abstract}

\section{Introduction}

Due to the obvious properties of enhancing the efficiency of drugs in vivo, pharmaceutical nanocarriers including micelles, hydrogels, liposomes, and dendrimers (Figure 1) have been paid much attention in drug delivery system (DDS) [1-5]. Their obvious properties can be classified into two aspects: the nature properties of pharmaceutical nanocarriers, such as solubility, stability in vivo, and biodistribution [6]; the additional properties of pharmaceutical nanocarriers, such as longevity in the blood, passive or active targeting to the pathological sites, and responsiveness to local change in environmental conditions.

Differing from the nature properties of pharmaceutical nanocarriers, the additional properties of pharmaceutical nanocarriers can improve the efficiency of carried drugs not only by the nanometer region of the carriers but also by the artificiality of nanocarriers. The pharmaceutical nanocarriers as foreign particles are always opsonized and easily eliminated by mononuclear phagocytic system (MPS) before they accumulate in pathological sites through the circulatory. So long circulation is the primitive property of pharmaceutical nanocarriers, and the essential property for passive or active targeting and environmental responsibility of pharmaceutical nanocarriers [11]. Modifying certain polymers to the surface of pharmaceutical nanocarriers through physical adsorption or chemical grafting is the most effective way to increase the circulation time of pharmaceutical nanocarriers in vivo. The modified polymers should possess a well-solvated and flexible, immunogenic, and antigenic polymer chain, such as poly(ethylene glycol) (PEG) or poly(ethylene oxide) (PEO). The pharmaceutical nanocarriers with the property of long circulation can accumulate in the required pathological sites by passive or active targeting nanocarrier-based delivery systems. Passively-targeted nanocarriers are based on the properties of nanocarriers (such as size distribution and surface charge) and the disease pathology in order to spontaneously accumulate the nanocarriers in the pathological sites. Because of the high permeability of the vasculature and lack of lymphatic drainage in tumors and infarcted areas, the long-circulating pharmaceutical nanocarriers, whose size ranges from 10 to $500 \mathrm{~nm}$, can spontaneously accumulate in there by the EPR effect [12]. The actively targeted ability of long-circulating 


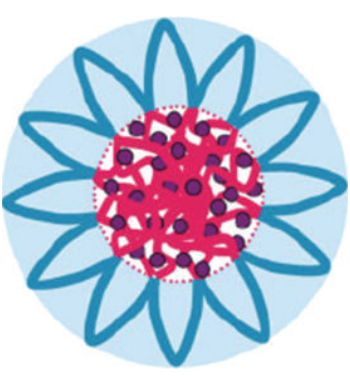

Polymeric micelles

(a)

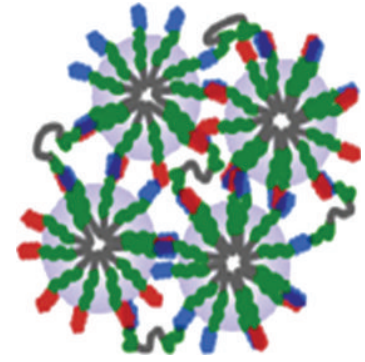

Nanostructured hydrogels

(b)

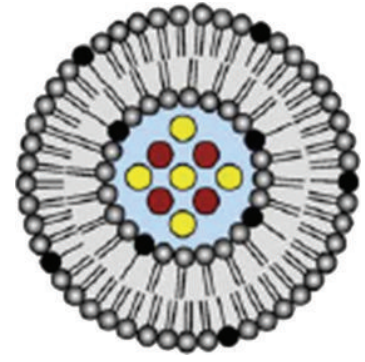

Liposomes

(c)

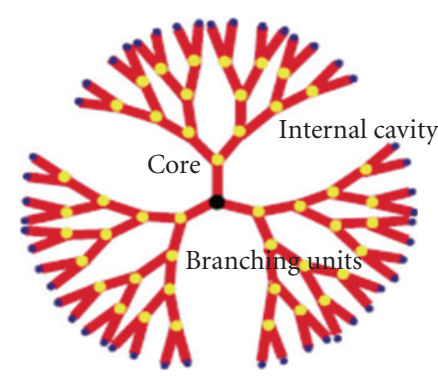

Fourth-generation dendrimers

(d)

FIgURE 1: Examples of thermosensitive nanocarriers (adapted from [7-10]).

pharmaceutical nanocarriers relies on attaching specific ligands (such as antibodies and peptides) to the nanocarriers surface that will be recognized by the cells presenting at the required pathological sites $[13,14]$. Figure 2 shows the potential application of the pharmaceutical nanocarriers for site-targeted drug delivery.

Environmental drug delivery system responding to different conditions, such as temperature, $\mathrm{pH}$, magnetic field, electric field, ultrasound, and so forth, has gained a great attention for controlled drug delivery [15-19]. Temperature is a typical example of "triggers" at the diseased site that could be exploited with nanocarriers. In fact, it would be most desirable if the drugs could be efficiently administered in a manner that precisely matches physiological needs at the proper sites and at proper times [20]. Nanocarriers with long circulation and thermosensitive properties offer a promising way to achieve these $[7,9,21]$. Firstly, because the thermosensitive nanocarriers specially accumulate in the required sites through passive or active targeting, the distribution of the carried drugs is efficiently controlled, and the side effects and waste of drugs are remarkablly limited. Moreover, when the nanocarriers reach the maximum acculturation in the required sites, the carried drugs are sustained released in response to changes in environmental temperature. With greater understanding of the difference between normal and pathological tissues and parallel advances of material design, there is a highly promising role of thermosensitive nanocarriers for controlled drug delivery in the future.

In this paper, we first discuss the functional properties of thermosensitive polymers in nanocarriers and classify thermosensitive polymers with a new perspective. Moreover, we describe the specific forms of thermosensitive nanocarriers in detail and discuss their characteristics of thermosensitive behavior and site-specific targeting.

\section{Functional Properties of Thermosensitive Polymers in Thermosensitive Nanocarriers}

In modern drug delivery technology, the status of thermosensitive nanocarriers is not only as traditional nanocarriers to increase stability and solubility or reduce immunogenicity and toxicity of carried drugs but also as functional nanocarriers to improve circulation time, passive target-specific delivery, and sustained release of drugs [22$24]$. By introducing thermosensitive polymers to prepare thermosensitive nanocarrier systems, these thermosensitive nanocarriers possess the ability of active response to the thermal changes of external environment [25].

The thermosensitive polymers can response to changes in temperature of the external environment, which results in the large change of its interesting features such as conformation, solubility, and hydrophilic/hydrophobic balance. These features are generally quantitatively described by the lower critical solution temperature (LCST). Thermosensitive polymer aqueous solution exhibits LCST phenomenon, below which polymer solution has one phase and above which they are phase-separated as a result of collapse and aggregation of polymer chains and expelled water [26]. It has to be noted that LCST is affected by the ratio of hydrophilic and hydrophobic monomers in thermosensitive polymers.

Dozens of reviews have classified thermosensitive polymers from the aspect of thermosensitive mechanism of polymers (polymers based on LCST and polymers based on amphiphilic balance) or composition of polymers (biopolymers with nature temperature responsive behavior and synthetic thermosensitive polymers) [27]. In order to discuss the functional properties of thermosensitive polymers in thermosensitive nanocarriers, we classified the thermosensitive polymers into two subclasses (Table 1). (a) Thermosensitive polymers as modified compounds endue nanocarriers with temperature responsive behavior [28-30]. The representative thermosensitive polymer of this type is Poly $(\mathrm{N}$-isopropyl acrylamide) (PIPAAm) [31-33]. The LCST of PIPAAm is 31$32.8^{\circ} \mathrm{C}$, above which it undergoes a reversible phase transition as a result of the coil-to-globule transition. Designed at the molecular level, the LCST of PIPAAm can be adjusted to around the physiological temperature of $37^{\circ} \mathrm{C}$ by introducing a hydrophilic comonomer, such as dimethylacrylamide (DMAAm) or acrylic acid (AAc). PIPAAm as modified compounds generally endue nanocarriers with temperature responsive behavior, such as micelles, liposomes, and solid nanocarriers. (b) Thermosensitive polymers as the main components of the nanocarrieres. In general, the structures of these thermosensitive polymers have two subcategories 


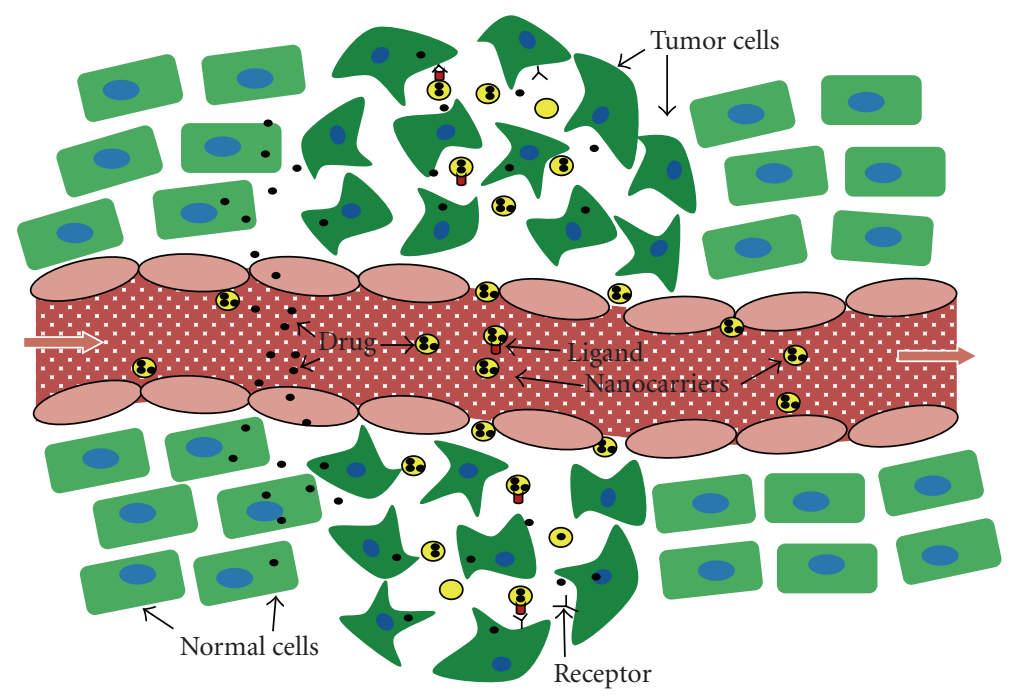

FIGURE 2: Schematic of nanocarriers for site-targeted drug delivery.

including linear structure and dendritic or heteroarm star structure [34, 35]. Amphiphilic block copolymers with $\mathrm{AB}$ type or $\mathrm{ABA}$ type are the well-known linear thermosensitive polymers, whose thermosensitive behavior is adjusted by shifting the hydrophilic/hydrophobic balance in its backbone [36-39]. Representatively, the poly(ethylene oxide)-poly(propylene oxide)-poly(ethylene oxide) (PEOPPO-PEO) triblock copolymer, known as Pluronic or Poloxamer, has been applied in controlled drug delivery due to its properties of temperature responsive micellization and gelation [40]. Differing from linear structure, the thermosensitive dendronized polymers undergo a sharper transition than linear thermosensitive polymers because their highly branched structure yields a small transition enthalpy in the phase transition process [41].

Though PIPAAm has been extensively studied for controlled drug delivery, its biomedical applications have been limited by some drawbacks such as possible presence of monomeric acrylamide-based residues (neurotoxin) and low biodegradability [42]. The similar drawbacks have also puzzled Poloxamers. Pluronics have poor biodegradability and have been found to induce hyperlipidemia and increase the plasma level of cholesterol in rabbits and rats [43]. In order to solve the above problems, a series of amphiphilic biodegradable block copolymers were synthesized by introducing a variety of biodegradable components such as poly(L-lactic acid) (PLLA) [44], poly(3-carprolactone) (PCL) [45, 46], and $\mathrm{PHB}[47,48]$ into the Pluronics copolymer backbone for enhancing the biodegradability of the thermosensitive polymers.

\section{Different Thermosensitive Nanocarrier Systems}

3.1. Thermosensitive Micelles. As known, amphiphilic block copolymers consisting of hydrophobic and hydrophilic blocks tend to form micelles in aqueous solution to reduce free energy mainly depending on hydrophobic interactions [49]. Due to the hydrophobic interactions among the hydrophilic segments of amphiphilic block copolymers, polymeric micelles which possess typical shell-core structure are self-assembled with the size ranging from 10 to $60 \mathrm{~nm}$ in aqueous solution (Figure 1(a)). The willowy hydrophilic shell cannot only provide a stabile structure of micelle but also escape from renal exclusion and the reticuloendothelial system. The hydrophobic core, meanwhile, can be used to solubilize hydrophobic drugs and protect the drug in the core from external interference. The critical micelles concentration (CMC) of polymeric micelles is much lower than that of surface acting agent. It means that micelles can spontaneously assemble very easily in the water at a low concentration of polymer. The nanograde size also enhances vascular permeability of micelles [50], especially at the solid tumor site. Therefore, the micelles were researched widely as nanocarriers for genes $[51,52]$, imaging agents $[53,54]$, and kinds of anticancer drugs [55-58].

Due to the different triggered parts of amphiphilic block copolymers, thermosensitive polymeric micelles can be categorized into two types (Table 2): polymeric micelles with thermosensitive outer shell and polymeric micelles with thermosensitive inner core. For the former type (Figure 3(a)), as their name implies, the thermosensitive character is possessed by the thermosensitive outer shells of the polymeric micelles. When the external environment temperature is above the phase transition temperature, the structure of polymeric micelles becomes instable and the carried drugs releases from the core, which result from the shrink and hydrophobicity of thermosensitive outer shell $[64,65]$. Teruo Okano and other groups prepared the former type of thermosensitive polymeric micelles, which were composed of thermosensitive PIPAAm blocks or P(IPAAm-co-DMAAm) blocks as the outer hydrophilic shell and hydrophobic PLA blocks or PBMA blocks as the drug-incorporated inner core $[66,67]$. PIPAAm is the most widely used thermosensitive 
TABLE 1: Classification of thermosensitive polymers from the aspect of their function in thermosensitive nanocarriers.

\begin{tabular}{|c|c|c|c|c|}
\hline $\begin{array}{l}\text { The type of } \\
\text { thermosensitive } \\
\text { polymer }\end{array}$ & $\begin{array}{c}\text { Representative } \\
\text { thermosensitive polymer }\end{array}$ & $\operatorname{LCST}\left({ }^{\circ} \mathrm{C}\right)$ & Application & References \\
\hline \multirow{6}{*}{$\begin{array}{l}\text { As the modified } \\
\text { compounds of } \\
\text { thermosensitive } \\
\text { nanocarriers }\end{array}$} & PIPAAm & $31-32.8$ & Modifying polymeric micelles & {$[31]$} \\
\hline & & & Modifying dendrimers & {$[32]$} \\
\hline & & & Modifying liposomes & {$[33]$} \\
\hline & poly(EOEOVE) & $40-45$ & Modifying liposomes & {$[28]$} \\
\hline & PDMA & $31-35$ & Modifying dendrimers & [29] \\
\hline & P(IPAAm-co-DMAAm) & $37-42.5$ & Modifying polymeric micelles & {$[30]$} \\
\hline \multirow{7}{*}{$\begin{array}{l}\text { As the main } \\
\text { component part } \\
\text { of the } \\
\text { thermosensitive } \\
\text { nanocarriers }\end{array}$} & PIPAAm-co-PCIPAAm & $32-37$ & Thermosensitive hydrogels & {$[34]$} \\
\hline & PEO-PPO-PEO & $5-30$ & Thermosensitive hydrogels & {$[40]$} \\
\hline & (DM-b-CD)-PEG-PPG & 37 & Thermosensitive hydrogels & {$[36]$} \\
\hline & PIPAAm-PBMA & 32.5 & Thermosensitive micelles & [37] \\
\hline & PIPAAm-PHB-PIPAAm & $28-29$ & Thermosensitive micelles & {$[38]$} \\
\hline & PLGA-PEG-PLGA & 37 & Thermosensitive micelles & {$[39]$} \\
\hline & $\begin{array}{c}\text { Biaryl-based G3 } \\
\text { dendrons with } \\
\text { pentaethylene glycol and } \\
\text { decyl chain }\end{array}$ & $32-42$ & Thermosensitive dendrimers & {$[35]$} \\
\hline
\end{tabular}

Poly(EVEOVE): poly(2-ethoxy) ethoxyethyl vinyl ether (EOEOVE); PDMA: poly(N,N-dimethylaminoethyl methacrylate); P(IPAAm-co-DMAAm): poly(Nisopropylacrylamide-co-N,N-dimethylacrylamide); PCIPAAm: poly(2-carboxyisopropylacrylamide); PEO: poly(ethylene oxide); PPO: poly(propylene oxide); DM-b-CD: heptakis (2,6-di-Omethyl)-b-cyclodextrin; PHB: Poly[(R)-3-hydroxybutyrate]; PLGA: poly(DL-lactic acid-co-glycolic acid).

polymer because of its phase transition temperature near the physiological temperature, and its phase transition temperature can be adjusted by introducing hydrophilic segments $[68,69]$. In order to sharpen thermoresponsiveness and obtain biodegradable properties of copolymers, they used PLA block instead of PBMA block [31]. In contrast with the former one, the latter type (Figure 3(b)) consists of hydrophobic blocks as the core played thermosensitive properties, such as acryloxy succinimide, pHPMAmDL, and HPMAm-Lacn. Once the environment temperature is above the LCST, the thermosensitive polymeric micelles are gradually destabilized due to hydrolysis of hydrophobic blocks [70]. Hennink and colleagues [61] prepared thermosensitive polymeric micelles consisting of pHPMAmDL-b-PEG block copolymers and investigated its drug release behaviors and cytotoxicity of the polymeric micellar formulation of loaded PTX in vitro. Through the polymerization of methacrylate groups and UV illumination, Rijcken and colleagues [62] prepared core cross-linked thermosensitive polymeric micelles with excellent physical stability and increased their accumulation at tumor sites.

To date, there are mainly two routes to achieve targeting drug delivery for the thermosensitive micelles. Firstly, micelles can accumulate passively in tumor site better than normal tissues, due to the EPR effect of vascular endothelia at the tumor tissues. Once circulating to tumor tissues where environmental temperature is above the LCST, the outer shells of these micelles will become hydrophobic and the apparent size of micelles increases through their aggregation. Thus, micelles may be selectively retained at these sites, resulting in the enhancement of drug efficiency by increasing its release at the target area [71]. In addition,

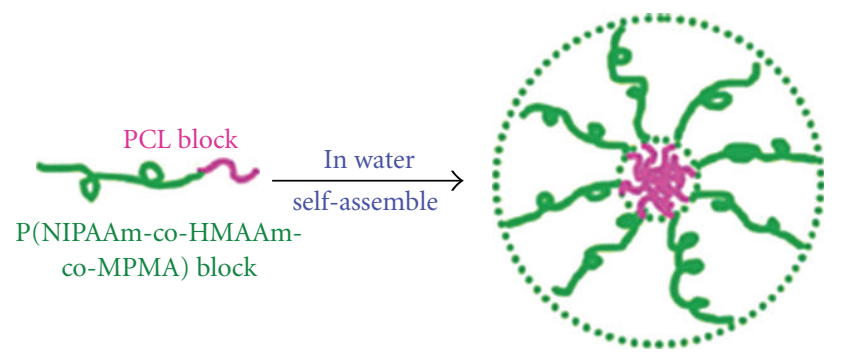

(a)

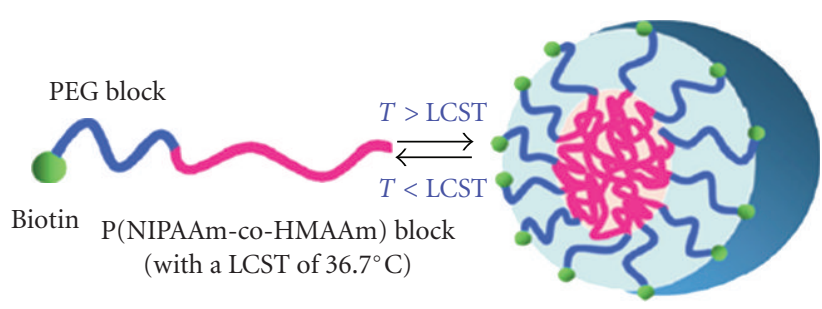

(b)

FIGURE 3: Schematic of the two types of thermosensitive micelles (adapted from [56, 71]).

the research $[37,68]$ demonstrated that dehydrated shell of micelles above the LCST can be uptaken by cells more easily than micelles below the LCST (Figure 4). A novel thermosensitive copolymer poly( $\mathrm{N}$-isopropylacrylamide-coacrylamide)-b-poly(DL-lactide) was synthesized for docetaxel carrier [72]. A significantly higher antitumor efficacy was observed in mice treated with docetaxel-loaded micelles 
TABLE 2: Thermosensitive micelles for the drug delivery.

\begin{tabular}{|c|c|c|c|c|c|}
\hline $\begin{array}{l}\text { Type of } \\
\text { thermosensitive } \\
\text { micelles }\end{array}$ & $\begin{array}{l}\text { Composition of } \\
\text { thermosensitive micelles }\end{array}$ & $\begin{array}{l}\text { Encapsulated } \\
\text { drug }\end{array}$ & $\operatorname{LCST}\left({ }^{\circ} \mathrm{C}\right)$ & Therapeutic outcome & References \\
\hline \multirow{5}{*}{$\begin{array}{l}\text { Thermo-responsive } \\
\text { shell }\end{array}$} & PBMA -PIPAAm & $\mathrm{ADR}$ & 32.5 & $\begin{array}{l}\text { Thermoresponsive } \\
\text { release by the changes } \\
\text { of the LCST }\end{array}$ & {$[37]$} \\
\hline & $\begin{array}{c}\text { PDLLA } \\
\text { a-P(IPAAm-co-DMAAm) }\end{array}$ & $\mathrm{ADR}$ & $37-42.5$ & $\begin{array}{l}\text { Control of ADR } \\
\text { cytotoxic activity by } \\
\text { temperature and } \\
\text { effective target therapy }\end{array}$ & {$[30]$} \\
\hline & PCL-PIPAAm & $\mathrm{CNZ}$ & $29.5-35.2$ & $\begin{array}{l}\text { Showed enhanced } \\
\text { sustained drug release }\end{array}$ & [59] \\
\hline & PCL-PIPAAm-PCL & PA & $35.8-36.2$ & $\begin{array}{l}\text { Showed enhanced } \\
\text { thermosensitive } \\
\text { controlled release } \\
\text { behaviors }\end{array}$ & [7] \\
\hline & $\begin{array}{c}\text { PLGA-P } \\
\text { (IPAAm-co-DMAAm) }\end{array}$ & DOX & $37-39.5$ & $\begin{array}{l}\text { Effective nuclei } \\
\text { therapy and greater } \\
\text { cytotoxicity above the } \\
\text { LCST }\end{array}$ & {$[60]$} \\
\hline \multirow[t]{3}{*}{$\begin{array}{l}\text { Thermo-responsive } \\
\text { core }\end{array}$} & $\begin{array}{l}\text { P(IPAAm-co-HMAAm)- } \\
\text { biotin-PEG }\end{array}$ & MTX & 41 & $\begin{array}{l}\text { About } 90 \% \text { of the } \\
\text { drug is released from } \\
\text { the micelles in } 96 \mathrm{~h} \text { at } \\
37^{\circ} \mathrm{C}\end{array}$ & {$[56]$} \\
\hline & pHPMAmDL-b-PEG & PTX & $10-65$ & $\begin{array}{l}70 \% \text { of PTX is released } \\
\text { in } 20 \mathrm{~h} \text { at } 37^{\circ} \mathrm{C}\end{array}$ & {$[61]$} \\
\hline & $\mathrm{p}$ (HEMAm-Lacn)-b-mPEG & - & $0-37.5$ & $\begin{array}{l}\text { A superior circulation } \\
\text { profile and enhanced } \\
\text { thermosensitive } \\
\text { controlled release } \\
\text { behaviors }\end{array}$ & {$[62,63]$} \\
\hline
\end{tabular}

PBMA: poly(butylmethacrylate); PDLLA: poly(D,L-lactide); PCL: poly(e-caprolactone); P(NIPAAm-co-HMAAm): poly(N-isopropylacrylamide-co-Nhydroxymethylacrylamide); ADR: adriamycin; pHPMAmDL: poly(N-(2-hydroxypropyl) methacrylamide lactate); PA: prednisone acetate; $\mathrm{p}(\mathrm{HEMAm}-\mathrm{Lacn})$ : poly(N-(2-hydroxyethyl)methacrylamide)-oligolactates); CNZ: clonazepam; DOX: doxorubicin; MTX: methotrexate; PTX: paclitaxel.

accompanied by hyperthermia compared with the conventional docetaxel formulation. When a drug is partitioned into dense micelles, the systemic concentration of free drug is decreased, which diminishes intracellular drug uptake by normal cells and reduces unwanted side effects caused by drug interactions with healthy tissues. However, when drug is encapsulated in micelles, its uptake by cancerous cells is also decreased [73]. Therefore, another effective method cancer therapy is triggering the drug release from the micelles at the tumor site [74].

3.2. Thermosensitive Hydrogels. Thermosensitive hydrogels are three-dimensional hydrophilic polymer networks capable of imbibing large amounts of water or biological fluids (Figure 1(b)), which can either be synthesized to degrade at a certain rate or to respond to temperature stimuli in the body [75]. These systems undergo a reversible volume phase transition with a change in the temperature of the environmental conditions. This type of behavior is related to polymer phase separation as the temperature rises to a critical value known as the LCST [24]. Networks exhibiting
LCST tend to shrink or collapse as the temperature increases above the LCST. Changes of the local temperature could lead to gel swelling or collapse. In these situations, the release rates would be altered significantly. The swelling of these hydrogel beads in response to small changes in temperature can be successfully used to control drug release.

Thermosensitive hydrogels have been widely studied for biomedical and pharmaceutical applications, especially for drug delivery system [76-78]. These thermosensitive hydrogels as drug carriers not only provide a sustained release formulation but also enhance the stability of drugs. However, a great many of researches focused on improving controlledrelease properties of this thermosensitive hydrogel carriers based on the sol-gel transition [20], whereas the research for site-targeted drug delivery has been rarely reported until now. Indeed, these polymers have potential applications in site-targeted drug delivery, especially in delivering drug to tumor sites $[79,80]$.

Our group recently proposed a "novel thermosensitive hydrogel" for site-targeted drug delivery (Figure 5) [81, 82]. We used the PLGA-PEG-PLGA hydrogel to fabricate the novel thermosensitive nanocarriers. The sol-gel transition 


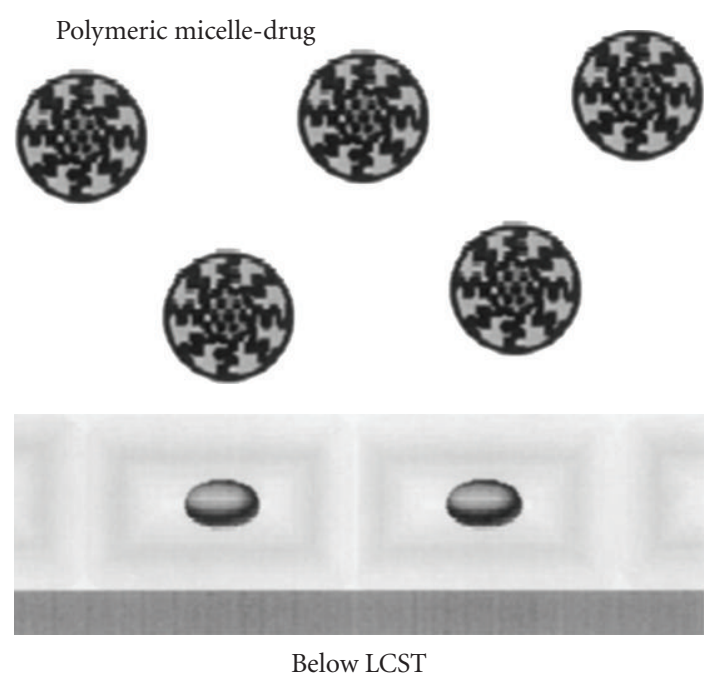

(a)

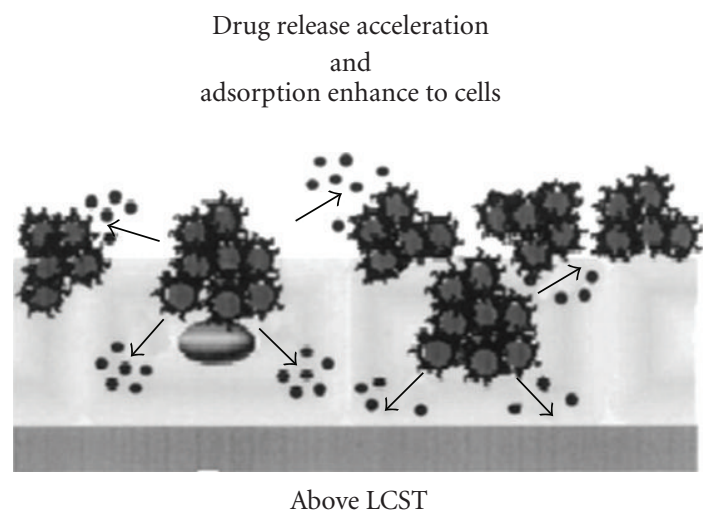

(b)

FIGURE 4: Schematic of thermosensitive micelles for site-targeted drug delivery (cited from [37]).

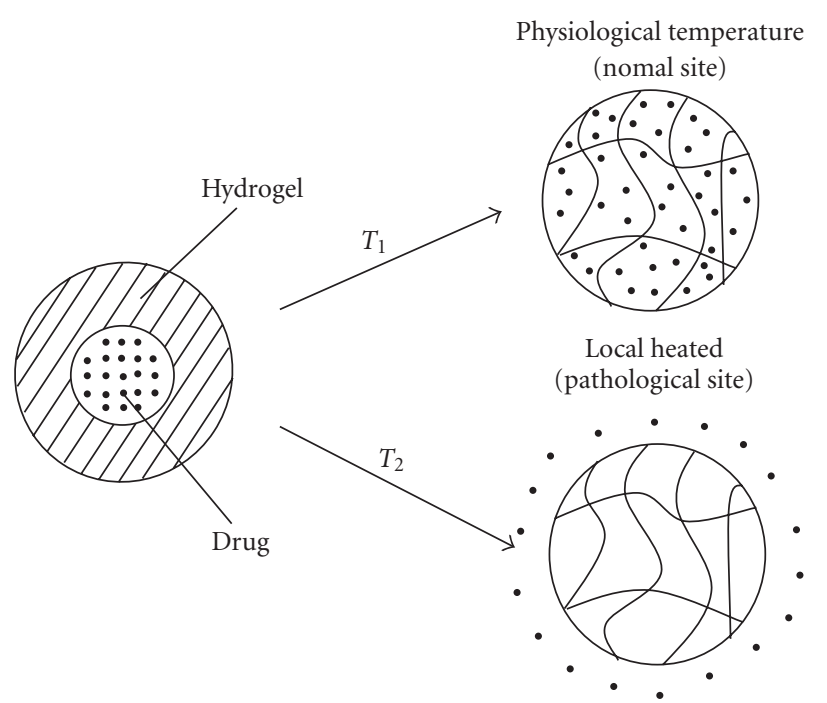

Figure 5: Thermosensitive nanocarriers for site-targeted delivery.

temperature $\left(\mathrm{T}_{1}\right)$ of the hydrogel was below the body temperature, and the gel-sol transition temperature $\left(\mathrm{T}_{2}\right)$ was greater than the physiological temperature but less than the temperature that the body can bear, about $40-44^{\circ} \mathrm{C}$. Our studies also suggested that the drug release of the nanocarriers had none or a little at the physiological temperature, while at the high temperature, about $42^{\circ} \mathrm{C}$, it had large. In this way, thermosensitive drug delivery system can undergo reversible structural transitions from a closed state to an open state with the help of external temperature stimuli, giving on-off switches for modulated drug delivery (Figure 6).

3.3. Thermosensitive Liposomes. Liposomes are spherical, self-enclosed structures formed by a phospholipid bilayer surrounding an aqueous inner compartment (Figure 1(c)).

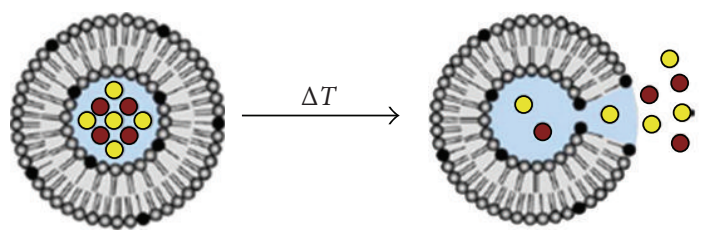

(a)
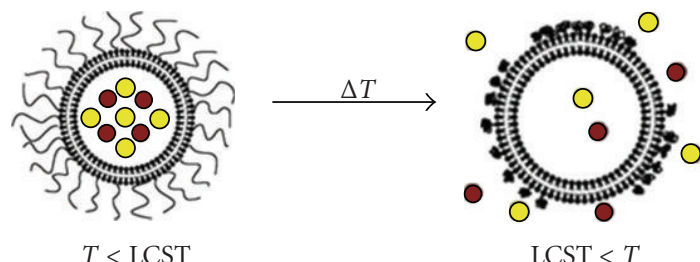

(b)

FIGURE 6: Schematic of the two types of thermosensitive liposomes (adapted from $[9,85]$ ).

Liposomes, about $100 \mathrm{~nm}$ in diameter, can accumulate only in perivascular regions in tumor tissues after i.v. injection. Conventional liposomes have been clinically evaluated and approved in a variety of diseases [83]. Undoubtedly, drug leaking out of liposomes accumulates in tumor tissues, where slow release provides therapeutic benefit and may be efficacious. However, antitumor efficacy has often been limited by slow release of bioavailable drug within the tumor [84]. Thus, the ability to control and produce a burst release would be extremely advantageous.

The effective combination of functional head groups, lipid chains, and linker groups in membrane components can achieve controlled stability of the liposomal membrane and selective release of encapsulated material under specific environmental conditions. Several release mechanisms, most being thermosensitive, have been described [86-88]. 
Generally, thermosensitive liposomes make use of lipids with transition temperatures between 40 and $45^{\circ} \mathrm{C}$ [89-91] The application of this type of liposome in combination with local hyperthermia can be used for specific drug release in solid tumors. Thus, thermosensitive liposomes have been studied for chemotherapeutic purposes to enhance the release of anticancer drugs at tumor sites.

The traditional strategy for the production of thermosensitive liposomes is based on the theory that once the ambient temperature is near the gel-to-liquid crystalline phase transition temperature of liposome, the liposome becomes destabilized and leaks carried drug (Figure 6(a)). However, in order to obtain excellent drug release kinetics and various thermosensitive functionalities, another strategy for preparing thermosensitive liposomes is conjugating thermosensitive polymers, as triggered parts of thermosensitive liposomes, in liposomal membranes (Figure 6(b)) [33]. The liposome is stabilized by highly hydrated polymer chains, when the environmental temperature is below the LCST of thermosensitive polymers. Once the environmental temperature is above their LCST, the liposome becomes destabilized due to the dehydration and contraction of the polymer chains.

Thermosensitive polymers are fixed on liposomal membranes by anchors, which have hydrophobic side groups or amino groups at the end of chain. The method of fixed thermosensitive polymers can be categorized into two types: anchors connected randomly to the polymer backbone and anchors connected specifically to the end of the polymer chain [85]. Kono and colleagues reported that the liposomes modified with a terminal anchor-type polymer possess a significant improvement of the drugs release in a narrow temperature region. By living cationic polymerization, they also [28] prepared thermosensitive polymer modifed liposomes, in which poly(EOEOVE) block acts as a thermosensitive moiety and the poly(octadecyl vinyl ether) (ODVE) block plays as an anchor between the liposome membrane and octadecyl chains of thermosensitive moiety, and found that a longer polymer chain can enhance drug release within a narrow temperature region.

The temperature-dependent effect can be strongly increased by the use of thermosensitive liposomes in combination with local hyperthermia which specifically release the entrapped drug in the heated tumor tissue [9294]. Needham and colleagues [93] focused on developing a new thermal-sensitive drug delivery system containing DOX that has been optimized for both mild hyperthermic temperatures that are readily achievable in the clinic and rapid release times of drug. Their studies showed the advantages of the new lipid composition compared with existing liposome formulations. The studies also exhibited that novel thermosensitive liposome, in combination with mild hyperthermia, was found to be significantly more effective than free drug or current liposome formulations for reducing tumor growth in a human squamous cell carcinoma xenograft line. The studies by Han and colleagues [94] have shown that the antitumor activity of thermosensitive liposomes was enhanced significantly when they were administered in combination with hyperthermia. And the liposomes were also found to be highly efficacious carriers for in vivo delivery of anticancer drugs.

3.4. Thermosensitive Dendrimers. Dendrimers (Figure 1(d)) serve as nanoscopic drug carriers due to their unique architecture and properties, such as high controllability of structure, surface properties, and size. By the physically entrapped or chemically conjugated, many commercial drugs can be efficaciously incorporated into dendrimers $[95,96]$. Due to increasing therapeutic effects of the drugloaded dendrimers, the dendrimers with thermosensitive properties have been extensively investigated for controlled drug delivery system [97-99].

The initial strategy for providing thermosensitive properties to dendrimers is preparing the thermosensitive dendrimers with core-shell nanostructure by modifying the outer dendrimer surface with thermosensitive polymers (Table 3). Much attention has been paid to graft PIPAAm to chain ends of dendrimers [32, 100]. However, these PIPAAm-modified dendrimers lose their significant characteristic of molecular uniformity due to the fundamentally polydisperse morphology of PIPAAm chains. To improve this situation, Haba and colleagues [99] introduced IBAM group, a common structural unit with thermosensitive poly $(\mathrm{N}-$ vinylisobutyramide), to the chain end of PAMAM dendrimers. It is another method for modifying dendrimers. In order to achieve double thermosensitive dendrimers, $\mathrm{Xu}$ and colleagues [102] prepared core-shell-corona nanostructures with hydrophobic $\mathrm{H} 40$ as the core, swollen PNIPAM as the inner shell, and swollen PDMA as the corona (Figure 7).

The later strategy for functionalization of thermosensitive dendrimers is building branched macromolecules constructed with hydrophilic and hydrophobic units. Various LCSTs of thermosensitive dendrimers are ensured by the different rates of hydrophilic and hydrophobic units in their backbone. It is noteworthy that the thermosensitive properties of these dendrimers are based on their amphiphilic dendronized polymers, rather than grafting thermosensitive polymers to the dendrimers surface. Aathimanikandan and colleagues [35] synthesized amphiphilic dendrimers with pentaethylene glycol as the hydrophilic part and a decyl chain as the hydrophobic part, which exhibits thermosensitive behavior and possesses possibility of utilizing for nanocarriers.

\section{Conclusions and Future Perspective}

Thermosensitive nanocarriers have been regarded as a safe and effective drug delivery vehicle, due to their unique capability of loading a large amount of various drugs, long circulation in the bloodstream, accumulation in tumor tissues by EPR effect, biological compatibility, and remote controlled drug release in response to mild heating. Though thermosensitive nanocarriers possess the above advantages in drug delivery, this system still needs to be continuously improved to meet the needs of clinical applications.

To improve content release efficiency, the phase transition temperature $(\mathrm{Tp})$ of thermosensitive nanocarriers 
TABLE 3: Classification of thermosensitive dendrimers.

\begin{tabular}{|c|c|c|c|c|}
\hline \multirow{2}{*}{ Strategy } & \multicolumn{2}{|c|}{ Architecture } & \multirow{2}{*}{$\operatorname{LCST}\left({ }^{\circ} \mathrm{C}\right)$} & \multirow{2}{*}{ References } \\
\hline & Dendritic core & Temoerature-sensitive shell & & \\
\hline \multirow{9}{*}{$\begin{array}{l}\text { Thermosensitive } \\
\text { polymers } \\
\text { modified } \\
\text { dendrimers }\end{array}$} & DAB-dendr-SCOCH$/ 3 /-S H$ & PIPAAm & $34-36$ & {$[32]$} \\
\hline & $\begin{array}{c}\text { Dithiobenzoate-terminated } \\
\text { dendrimer }\end{array}$ & PIPAAm & $25-35$ & {$[100]$} \\
\hline & PAMAM/ PPI & IBAM-G ${ }_{1-5}$ & $20-60$ & {$[99,101]$} \\
\hline & PAMAM & PDMA & $31-35$ & [29] \\
\hline & Bolton $\mathrm{H} 40$ & $\begin{array}{l}\text { IPAAm } \\
\text { DMA }\end{array}$ & $\begin{array}{c}32 \\
40-50\end{array}$ & {$[102]$} \\
\hline & PAMAM & Phe residues or & $20-30$ & {$[97]$} \\
\hline & 1 & Ile residues & - & \\
\hline & Dex-AI & PIPAAm & 25.7 & {$[103]$} \\
\hline & PAMAM & PIPAAm & 33 & {$[104]$} \\
\hline \multirow{2}{*}{$\begin{array}{l}\text { Amphiphilic } \\
\text { dendrimers }\end{array}$} & \multicolumn{2}{|c|}{ Biaryl-based G3 dendrons with pentaethylene glycol and decyl chain } & $32-42$ & {$[35]$} \\
\hline & \multicolumn{2}{|c|}{$\begin{array}{l}\text { Branched 3-fold polymethacrylate derivatives, gallic acid as } \\
\text { branching point, TEG units as linker }\end{array}$} & $62-65$ & {$[105]$} \\
\hline
\end{tabular}

PPI: poly(propylenimine); IBAM: isobutyramide; PAMAM: polyamidoamine; Dex-AI, dextran-allyl isocyanate.
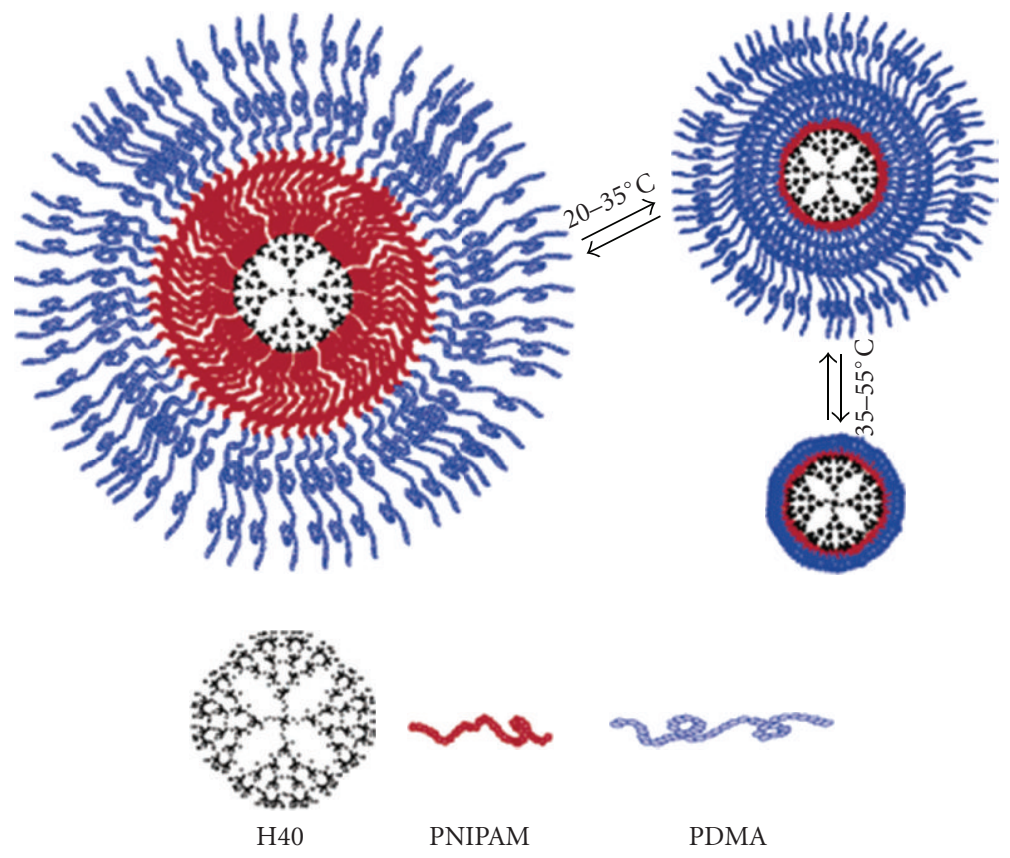

FIGURE 7: Schematic illustration of the double thermosensitive dendrimers (cited from [102]).

should be in the following specifying points: (a) the Tp should be near the physiological temperature (about $37^{\circ} \mathrm{C}$ ) but not below this temperature resulting in none or a little drug release before being under local hyperthermia [106]; (b) the Tp should be less than the temperature that the body can bear and within a very narrow temperature range (about 4-5 $\left.{ }^{\circ} \mathrm{C}\right)$ [107]; (c) the structures of thermosensitive nanocarriers should be significantly changed once near the Tp in order to shorten the time of the release reaching the maximum [108]. So it is necessary to synthesize the thermosensitive polymers with better-controlled structures to precisely adjust the LCST. The development of thermosensitive polymers synthesis from free-radical and anionic polymerization to controlled radical and cationic polymerization offers a way to realize it [109]. Recently, establishing the thermosensitive macromolecules with the supramolecular organization such as star-shaped [110] or highly branched architectures [111] was another successful chance to achieve it.

The subsequent accumulation of the thermosensitive nanocarriers in the target sites still remains a challenge due to the limitations of passive targeting drug delivery. The multifunctional thermosensitive nanocarriers which conjugated with different ligands such as avidin [56] or folate [112] are the current trend to optimize these sitespecific therapeutic systems. It is noteworthy that thermosensitive nanocarriers change not only their behaviors of 
drug release but also their behaviors of intracellular uptake in response to the change of environmental temperature. Thermosensitive nanocarriers which possess PIPAAm-based outer coronas can enhance interactions between the micelles and cell membranes through the dehydration of coronaforming thermosensitive polymer chains, and the micelles localize at the Golgi apparatus and endoplasmic reticulum [113]. It indicates that thermosensitive nanocarriers are greatly promising as intracellular delivery vehicles to intracellular targeted drug delivery in conjunction with applied heating. Due to the different accumulation processes of thermosensitive nanocarriers among individual patients, it is critical to determine the maximum acculturation of the nanocarriers in the target sites before triggered drug release from the nanocarriers. In order to overcome this problem, it is necessary to provide imaging functions to the carrier by incorporating various imaging probes, for example, magnetic resonance imaging (MRI) probes [114]. Under the high detectability with MRI, the accumulation and drug release of the thermosensitive nanocarriers are remotely controlled [115]. It provides a way to engender the efficient patient-optimized therapy.

Thermosensitive nanocarriers have already been used for a wide range of applications in controlled drug delivery. The large number of available approaches to generate these smart nanocarriers illustrates the versatility of the system and the great potential to be explored for future applications.

\section{Acknowledgment}

This study was supported by the Fundamental Research Funds for the Central Universities (Project no. CDJRC10230003).

\section{References}

[1] G. A. Hughes, "Nanostructure-mediated drug delivery," Nanomedicine: Nanotechnology, Biology, and Medicine, vol. 1, no. 1, pp. 22-30, 2005.

[2] A. Kumari, S. K. Yadav, and S. C. Yadav, "Biodegradable polymeric nanoparticles based drug delivery systems," Colloids and Surfaces B, vol. 75, no. 1, pp. 1-18, 2010.

[3] M. Rawat, D. Singh, and S. Saraf, "Nanocarriers: promising vehicle for bioactive drugs," Biological and Pharmaceutical Bulletin, vol. 29, no. 9, pp. 1790-1798, 2006.

[4] D. Peer, J. M. Karp, S. Hong, O. C. Farokhzad, R. Margalit, and R. Langer, "Nanocarriers as an emerging platform for cancer therapy," Nature Nanotechnology, vol. 2, no. 12, pp. 751-760, 2007.

[5] M. N. V. Ravi Kumar, U. Bakowsky, and C. M. Lehr, "Preparation and characterization of cationic PLGA nanospheres as DNA carriers," Biomaterials, vol. 25, no. 10, pp. 1771-1777, 2004.

[6] S. D. Li and L. Huang, "Pharmacokinetics and biodistribution of nanoparticles," Molecular Pharmaceutics, vol. 5, no. 4, pp. 496-504, 2008.

[7] C. Chang, H. Wei, C. Y. Quan et al., "Fabrication of thermosensitive PCL-PNIPAAm-PCL triblock copolymeric micelles for drug delivery," Journal of Polymer Science A, vol. 46, no. 9, pp. 3048-3057, 2008.
[8] H. J. Chung and T. G. Park, "Self-assembled and nanostructured hydrogels for drug delivery and tissue engineering," Nano Today, vol. 4, no. 5, pp. 429-437, 2009.

[9] M. de Smet, S. Langereis, S. V. den Bosch, and H. Grüll, "Temperature-sensitive liposomes for doxorubicin delivery under MRI guidance," Journal of Controlled Release, vol. 143, no. 1, pp. 120-127, 2010.

[10] S. K. Sahoo and V. Labhasetwar, "Nanotech approaches to drug delivery and imaging," Drug Discovery Today, vol. 8, no. 24, pp. 1112-1120, 2003.

[11] S. Ganta, H. Devalapally, A. Shahiwala, and M. Amiji, "A review of stimuli-responsive nanocarriers for drug and gene delivery," Journal of Controlled Release, vol. 126, no. 3, pp. 187-204, 2008.

[12] V. Torchilin, "Tumor delivery of macromolecular drugs based on the EPR effect," Advanced Drug Delivery Reviews, vol. 63, no. 3, pp. 131-135, 2010.

[13] V. P. Torchilin, "Multifunctional nanocarriers," Advanced Drug Delivery Reviews, vol. 58, no. 14, pp. 1532-1555, 2006.

[14] R. Langer, "Drugs on target," Science, vol. 293, no. 5527, pp. 58-59, 2001.

[15] J. C. Sung, B. L. Pulliam, and D. A. Edwards, "Nanoparticles for drug delivery to the lungs," Trends in Biotechnology, vol. 25, no. 12, pp. 563-570, 2007.

[16] L. Paasonen, T. Laaksonen, C. Johans, M. Yliperttula, K. Kontturi, and A. Urtti, "Gold nanoparticles enable selective light-induced contents release from liposomes," Journal of Controlled Release, vol. 122, no. 1, pp. 86-93, 2007.

[17] S. K. Deo, E. A. Moschou, S. F. Peteu et al., "Responsive drug delivery systems," Analytical Chemistry, vol. 75, no. 9, pp. 206A-213A, 2003.

[18] M. A. Casadei, G. Pitarresi, R. Calabrese, P. Paolicelli, and G. Giammona, "Biodegradable and $\mathrm{pH}$-sensitive hydrogels for potential colon-specific drug delivery: characterization and in vitro release studies," Biomacromolecules, vol. 9, no. 1, pp. 43-49, 2008.

[19] S. Chen, Y. Li, C. Guo et al., "Temperature-responsive magnetite/PEO-PPO-PEO block copolymer nanoparticles for controlled drug targeting delivery," Langmuir, vol. 23, no. 25, pp. 12669-12676, 2007.

[20] Y. Qiu and K. Park, "Environment-sensitive hydrogels for drug delivery," Advanced Drug Delivery Reviews, vol. 53, no. 3, pp. 321-339, 2001.

[21] X. J. Loh, P. Peh, S. Liao, C. Sng, and J. Li, "Controlled drug release from biodegradable thermoresponsive physical hydrogel nanofibers," Journal of Controlled Release, vol. 143, no. 2, pp. 175-182, 2010.

[22] S. Kim, J. H. Kim, O. Jeon, I. C. Kwon, and K. Park, "Engineered polymers for advanced drug delivery," European Journal of Pharmaceutics and Biopharmaceutics, vol. 71, no. 3, pp. 420-430, 2009.

[23] J. Li, B. C. Wang, and Y. Z. Wang, "Thermo-sensitive polymers for controlled-release drug delivery systems," International Journal of Pharmacology, vol. 2, no. 5, pp. 513-519, 2006.

[24] A. K. Bajpai, S. K. Shukla, S. Bhanu, and S. Kankane, "Responsive polymers in controlled drug delivery," Progress in Polymer Science, vol. 33, no. 11, pp. 1088-1118, 2008.

[25] D. Schmaljohann, "Thermo- and $\mathrm{pH}$-responsive polymers in drug delivery," Advanced Drug Delivery Reviews, vol. 58, no. 15, pp. 1655-1670, 2006.

[26] J. Kost and R. Langer, "Responsive polymeric delivery systems," Advanced Drug Delivery Reviews, vol. 46, no. 1-3, pp. 125-148, 2001. 
[27] E. S. Gil and S. M. Hudson, "Stimuli-reponsive polymers and their bioconjugates," Progress in Polymer Science, vol. 29, no. 12, pp. 1173-1222, 2004.

[28] K. Kono, T. Murakami, T. Yoshida et al., "Temperature sensitization of liposomes by use of thermosensitive block copolymers synthesized by living cationic polymerization: effect of copolymer chain length," Bioconjugate Chemistry, vol. 16, no. 6, pp. 1367-1374, 2005.

[29] H. Hu, X. D. Fan, and Z. L. Cao, "Thermo- and pHsensitive dendrimer derivatives with a shell of poly $(\mathrm{N}, \mathrm{N}$ dimethylaminoethyl methacrylate) and study of their controlled drug release behavior," Polymer, vol. 46, no. 22, pp. 9514-9522, 2005.

[30] F. Kohori, K. Sakai, T. Aoyagi et al., "Control of adriamycin cytotoxic activity using thermally responsive polymeric micelles composed of poly(N-isopropylacrylamide-co-N,Ndimethylacrylamide)-b-poly(D,L-lactide)," Colloids and Surfaces B, vol. 16, no. 1-4, pp. 195-205, 1999.

[31] M. Nakayama, T. Okano, T. Miyazaki, F. Kohori, K. Sakai, and M. Yokoyama, "Molecular design of biodegradable polymeric micelles for temperature-responsive drug release," Journal of Controlled Release, vol. 115, no. 1, pp. 46-56, 2006.

[32] M. Kimura, M. Kato, T. Muto, K. Hanabusa, and H. Shirai, "Temperature-sensitive dendritic hosts: synthesis, characterization, and control of catalytic activity," Macromolecules, vol. 33, no. 4, pp. 1117-1119, 2000.

[33] H. Hayashi, K. Kono, and T. Takfagishi, "Temperature sensitization of liposomes using copolymers of $\mathrm{N}$ isopropylacrylamide," Bioconjugate Chemistry, vol. 10, no. 3, pp. 412-418, 1999.

[34] M. Ebara, T. Aoyagi, K. Sakai, and T. Okano, "Introducing reactive carboxyl side chains retains phase transition temperature sensitivity in $\mathrm{N}$-isopropylacrylamide copolymer gels," Macromolecules, vol. 33, no. 22, pp. 8312-8316, 2000.

[35] S. V. Aathimanikandan, E. N. Savariar, and S. Thayumanavan, "Temperature-sensitive dendritic micelles," Journal of the American Chemical Society, vol. 127, no. 42, pp. 1492214929, 2005.

[36] C. Yang, X. Ni, and J. Li, "New thermogelling copolymers composed of heptakis(2,6-di-O-methyl)- $\beta$ - cyclodextrin, poly(propylene glycol), and poly(ethylene glycol)," Journal of Materials Chemistry, vol. 19, no. 1, pp. 3755-3763, 2009.

[37] J. E. Chung, M. Yokoyama, M. Yamato, T. Aoyagi, Y. Sakurai, and T. Okano, "Thermo-responsive drug delivery from polymeric micelles constructed using block copolymers of poly(N-isopropylacrylamide) and poly(butylmethacrylate)," Journal of Controlled Release, vol. 62, no. 1-2, pp. 115-127, 1999.

[38] X. J. Loh, Z. X. Zhang, Y. L. Wu, T. S. Lee, and J. $\mathrm{Li}$, "Synthesis of novel biodegradable thermoresponsive triblock copolymers based on poly[(R)-3-hydroxybutyrate] and poly(N-isopropylacrylamide) and their formation of thermoresponsive micelles," Macromolecules, vol. 42, no. 1, pp. 194-202, 2009.

[39] P. Liu, B. Wang, W. Qiao, and J. Li, "Novel thermosensitive nano-micelles from triblock copolymer for drug delivery," Journal of Biomedical Nanotechnology, vol. 5, no. 3, pp. 310313, 2009.

[40] C. He, S. W. Kim, and D. S. Lee, "In situ gelling stimulisensitive block copolymer hydrogels for drug delivery," Journal of Controlled Release, vol. 127, no. 3, pp. 189-207, 2008.
[41] Y. Haba, C. Kojima, A. Harada, and K. Kono, "Comparison of thermosensitive properties of poly(amidoamine) dendrimers with peripheral $\mathrm{N}$-isopropylamide groups and linear polymers with the same groups," Angewandte Chemie: International Edition, vol. 46, no. 1-2, pp. 234-237, 2007.

[42] K. Hashimoto, J. Sakamoto, and H. Tanii, "Neurotoxicty of acrylamide and related compounds and their effects on male gonads in mice," Archives of Toxicology, vol. 47, no. 3, pp. 179189, 1981.

[43] X. J. Loh, S. H. Goh, and J. Li, "New biodegradable thermogelling copolymers having very low gelation concentrations," Biomacromolecules, vol. 8, no. 2, pp. 585-593, 2007.

[44] X. J. Loh, Y. X. Tan, Z. Li, L. S. Teo, S. H. Goh, and J. Li, "Biodegradable thermogelling poly(ester urethane)s consisting of poly(lactic acid)-thermodynamics of micellization and hydrolytic degradation," Biomaterials, vol. 29, no. 14, pp. 2164-2172, 2008.

[45] X. J. Loh, K. B. Colin Sng, and J. Li, "Synthesis and water-swelling of thermo-responsive poly(ester urethane)s containing polycaprolactone, poly(ethylene glycol) and poly(propylene glycol)," Biomaterials, vol. 29, no. 22, pp. 3185-3194, 2008.

[46] C. Gong, S. Shi, P. Dong et al., "Synthesis and characterization of PEG-PCL-PEG thermosensitive hydrogel," International Journal of Pharmaceutics, vol. 365, no. 1-2, pp. 89-99, 2009.

[47] X. J. Loh, S. H. Goh, and J. Li, "Hydrolytic degradation and protein release studies of thermogelling polyurethane copolymers," Biomaterials, vol. 28, no. 28, pp. 4113-4123, 2007.

[48] X. J. Loh, S. H. Goh, and J. Li, "Biodegradable thermogelling poly[(R)-3-hydroxybutyrate]-based block copolymers: micellization, gelation, and cytotoxicity and cell culture studies," Journal of Physical Chemistry B, vol. 113, no. 35, pp. 11822-11830, 2009.

[49] G. Riess, "Micellization of block copolymers," Progress in Polymer Science, vol. 28, no. 7, pp. 1107-1170, 2003.

[50] G. S. Kwon and T. Okano, "Polymeric micelles as new drug carriers," Advanced Drug Delivery Reviews, vol. 21, no. 2, pp. 107-116, 1996.

[51] H. Y. Tian, C. Deng, H. Lin et al., "Biodegradable cationic PEG-PEI-PBLG hyperbranched block copolymer: synthesis and micelle characterization," Biomaterials, vol. 26, no. 20, pp. 4209-4217, 2005.

[52] J. H. Jeong and T. G. Park, "Poly(L-lysine)-g-poly(D,L-lacticco-glycolic acid) micelles for low cytotoxic biodegradable gene delivery carriers," Journal of Controlled Release, vol. 82, no. 1, pp. 159-166, 2002.

[53] H. Otsuka, Y. Nagasaki, and K. Kataoka, "PEGylated nanoparticles for biological and pharmaceutical applications," Advanced Drug Delivery Reviews, vol. 55, no. 3, pp. 403-419, 2003.

[54] A. Harada and K. Kataoka, "Supramolecular assemblies of block copolymers in aqueous media as nanocontainers relevant to biological applications," Progress in Polymer Science, vol. 31, no. 11, pp. 949-982, 2006.

[55] L. Y. Qiu and Y. H. Bae, "Self-assembled polyethyleniminegraft-poly( $\varepsilon$-caprolactone) micelles as potential dual carriers of genes and anticancer drugs," Biomaterials, vol. 28, no. 28, pp. 4132-4142, 2007.

[56] C. Cheng, H. Wei, B. X. Shi et al., "Biotinylated thermoresponsive micelle self-assembled from double-hydrophilic block copolymer for drug delivery and tumor target," Biomaterials, vol. 29, no. 4, pp. 497-505, 2008. 
[57] S. Cai, K. Vijayan, D. Cheng, E. M. Lima, and D. E. Discher, "Micelles of different morphologies-advantages of worm-like filomicelles of PEO-PCL in paclitaxel delivery," Pharmaceutical Research, vol. 24, no. 11, pp. 2099-2109, 2007.

[58] H. Cabral, N. Nishiyama, S. Okazaki, H. Koyama, and K. Kataoka, "Preparation and biological properties of dichloro(1,2-diaminocyclohexane) platinum(II) (DACHPt)loaded polymeric micelles," Journal of Controlled Release, vol. 101, no. 1-3, pp. 223-232, 2005.

[59] C. Choi, S. Y. Chae, and J. W. Nah, "Thermosensitive poly(N-isopropylacrylamide)-b-poly( lunate-caprolactone) nanoparticles for efficient drug delivery system," Polymer, vol. 47, no. 13, pp. 4571-4580, 2006.

[60] S. Q. Liu, Y. W. Tong, and Y. Y. Yang, "Incorporation and in vitro release of doxorubicin in thermally sensitive micelles made from poly $(\mathrm{N}$-isopropylacrylamide-co-N,Ndimethylacrylamide)-b- poly(D,L-lactide-co-glycolide) with varying compositions," Biomaterials, vol. 26, no. 24, pp. 5064-5074, 2005.

[61] O. Soga, C. F. Van Nostrum, M. Fens et al., "Thermosensitive and biodegradable polymeric micelles for paclitaxel delivery," Journal of Controlled Release, vol. 103, no. 2, pp. 341-353, 2005.

[62] C. J. F. Rijcken, R. M. Schiffelers, C. F. van Nostrum, and W. E. Hennink, "Long circulating biodegradable polymeric micelles: towards targeted drug delivery," Journal of Controlled Release, vol. 132, no. 3, pp. e19-e36, 2008.

[63] C. J. Rijcken, C. J. Snel, R. M. Schiffelers, C. F. van Nostrum, and W. E. Hennink, "Hydrolysable core-crosslinked thermosensitive polymeric micelles: synthesis, characterisation and in vivo studies," Biomaterials, vol. 28, no. 36, pp. 55815593, 2007.

[64] S. Cammas, K. Suzuki, C. Sone, Y. Sakurai, K. Kataoka, and T. Okano, "Thermo-responsive polymer nanoparticles with a core-shell micelle structure as site-specific drug carriers," Journal of Controlled Release, vol. 48, no. 1-2, pp. 157-164, 1997.

[65] J. E. Chung, M. Yokoyama, and T. Okano, "Inner core segment design for drug delivery control of thermo-responsive polymeric micelles," Journal of Controlled Release, vol. 65, no. 1-2, pp. 93-103, 2000.

[66] H. Wei, X. Zhang, C. Cheng, S. X. Cheng, and R. X. Zhuo, "Self-assembled, thermosensitive micelles of a star block copolymer based on PMMA and PNIPAAm for controlled drug delivery," Biomaterials, vol. 28, no. 1, pp. 99-107, 2007.

[67] M. Nakayama, J. E. Chung, T. Miyazaki, M. Yokoyama, K. Sakai, and T. Okano, "Thermal modulation of intracellular drug distribution using thermoresponsive polymeric micelles," Reactive and Functional Polymers, vol. 67, no. 11, pp. 1398-1407, 2007.

[68] N. Takeda, E. Nakamura, M. Yokoyama, and T. Okano, "Temperature-responsive polymeric carriers incorporating hydrophobic monomers for effective transfection in small doses," Journal of Controlled Release, vol. 95, no. 2, pp. 343$355,2004$.

[69] M. Kurisawa, M. Yokoyama, and T. Okano, “Transfection efficiency increases by incorporating hydrophobic monomer units into polymeric gene carriers," Journal of Controlled Release, vol. 68, no. 1, pp. 1-8, 2000.

[70] C. J. F. Rijcken, O. Soga, W. E. Hennink, and C. F. van Nostrum, "Triggered destabilisation of polymeric micelles and vesicles by changing polymers polarity: an attractive tool for drug delivery," Journal of Controlled Release, vol. 120, no. 3, pp. 131-148, 2007.

[71] H. Wei, S. X. Cheng, X. Z. Zhang, and R. X. Zhuo, "Thermo-sensitive polymeric micelles based on poly $(\mathrm{N}$ isopropylacrylamide) as drug carriers," Progress in Polymer Science, vol. 34, no. 9, pp. 893-910, 2009.

[72] B. Liu, M. Yang, R. Li et al., "The antitumor effect of novel docetaxel-loaded thermosensitive micelles," European Journal of Pharmaceutics and Biopharmaceutics, vol. 69, no. 2, pp. 527-534, 2008.

[73] N. Rapoport, "Combined cancer therapy by micellarencapsulated drug and ultrasound," International Journal of Pharmaceutics, vol. 277, no. 1-2, pp. 155-162, 2004.

[74] M. Yokoyama and T. Okano, "Introduction: targetable drug carriers: present status and a future perspective," Advanced Drug Delivery Reviews, vol. 21, no. 2, pp. 77-80, 1996.

[75] N. A. Peppas, J. Z. Hilt, A. Khademhosseini, and R. Langer, "Hydrogels in biology and medicine: from molecular principles to bionanotechnology," Advanced Materials, vol. 18, no. 11, pp. 1345-1360, 2006.

[76] M. Hamidi, A. Azadi, and P. Rafiei, "Hydrogel nanoparticles in drug delivery," Advanced Drug Delivery Reviews, vol. 60, no. 15, pp. 1638-1649, 2008.

[77] J. Y. Fang, J. P. Chen, Y. L. Leu, and J. W. Hu, “Temperaturesensitive hydrogels composed of chitosan and hyaluronic acid as injectable carriers for drug delivery," European Journal of Pharmaceutics and Biopharmaceutics, vol. 68, no. 3, pp. 626636, 2008.

[78] S. Choi and S. W. Kim, "Controlled release of insulin from injectable biodegradable triblock copolymer depot in ZDF rats," Pharmaceutical Research, vol. 20, no. 12, pp. 2008-2010, 2003.

[79] S. W. Choi and J. H. Kim, "Design of surface-modified poly(d,l-lactide-co-glycolide) nanoparticles for targeted drug delivery to bone," Journal of Controlled Release, vol. 122, no. 1, pp. 24-30, 2007.

[80] N. Rapoport, "Physical stimuli-responsive polymeric micelles for anti-cancer drug delivery," Progress in Polymer Science, vol. 32, no. 8-9, pp. 962-990, 2007.

[81] J. Li, B. Wang, Y. Wang, P. Liu, and W. Qiao, "Preparation and characterization of thermosensitive nanoparticles for targeted drug delivery," Journal of Macromolecular Science A, vol. 45 , no. 10 , pp. 833-838, 2008.

[82] J. Li, B. Wang, and P. Liu, "Possibility of active targeting to tumor by local hyperthermia with temperature-sensitive nanoparticles," Medical Hypotheses, vol. 71, no. 2, pp. 249251, 2008.

[83] D. Felnerova, J. F. Viret, R. Glück, and C. Moser, "Liposomes and virosomes as delivery systems for antigens, nucleic acids and drugs," Current Opinion in Biotechnology, vol. 15, no. 6, pp. 518-529, 2004.

[84] X. Guo and F. C. Szoka, "Chemical approaches to triggerable lipid vesicles for drug and gene delivery," Accounts of Chemical Research, vol. 36, no. 5, pp. 335-341, 2003.

[85] K. Kono, "Thermosensitive polymer-modified liposomes," Advanced Drug Delivery Reviews, vol. 53, no. 3, pp. 307-319, 2001.

[86] S. Dromi, V. Frenkel, A. Luk et al., "Pulsed-high intensity focused ultrasound and low temperature-sensitive liposomes for enhanced targeted drug delivery and antitumor effect," Clinical Cancer Research, vol. 13, no. 9, pp. 2722-2727, 2007. 
[87] M. L. Hauck, S. M. La Rue, W. P. Petros et al., "Phase I trial of doxorubicin-containing low temperature sensitive liposomes in spontaneous canine tumors," Clinical Cancer Research, vol. 12, no. 13, pp. 4004-4010, 2006.

[88] Y. Yuyama, M. Tsujimoto, Y. Fujimoto, and N. Oku, "Potential usage of thermosensitive liposomes for site-specific delivery of cytokines," Cancer Letters, vol. 155, no. 1, pp. 7177, 2000.

[89] W. H. Chen and S. L. Regen, "Thermally gated liposomes," Journal of the American Chemical Society, vol. 127, no. 18, pp. 6538-6539, 2005.

[90] T. Hosokawa, M. Sami, Y. Kato, and E. Hayakawa, "Alteration in the temperature-dependent content release property of thermosensitive liposomes in plasma," Chemical and Pharmaceutical Bulletin, vol. 51, no. 11, pp. 1227-1232, 2003.

[91] L. H. Lindner, M. E. Eichhorn, H. Eibl et al., "Novel temperature-sensitive liposomes with prolonged circulation time," Clinical Cancer Research, vol. 10, no. 6, pp. 2168-2178, 2004.

[92] Q. Chen, S. Tong, M. W. Dewhirst, and F. Yuan, "Targeting tumor microvessels using doxorubicin encapsulated in a novel thermosensitive liposome," Molecular Cancer Therapeutics, vol. 3, no. 10, pp. 1311-1317, 2004.

[93] D. Needham, G. Anyarambhatla, G. Kong, and M. W. Dewhirst, "A new temperature-sensitive liposome for use with mild hyperthermia: characterization and testing in a human tumor xenograft model," Cancer Research, vol. 60, no. 5, pp. 1197-1201, 2000.

[94] H. D. Han, M. S. Choi, T. Hwang et al., "Hyperthermiainduced antitumor activity of thermosensitive polymer modified temperature-sensitive liposomes," Journal of Pharmaceutical Sciences, vol. 95, no. 9, pp. 1909-1917, 2006.

[95] U. Gupta, H. B. Agashe, A. Asthana, and N. K. Jain, "A review of in vitro-in vivo investigations on dendrimers: the novel nanoscopic drug carriers," Nanomedicine: Nanotechnology, Biology, and Medicine, vol. 2, no. 2, pp. 66-73, 2006.

[96] S. Svenson, "Dendrimers as versatile platform in drug delivery applications," European Journal of Pharmaceutics and Biopharmaceutics, vol. 71, no. 3, pp. 445-462, 2009.

[97] Y. Tono, C. Kojima, Y. Haba et al., "Thermosensitive properties of poly(amidoamine) dendrimers with peripheral phenylalanine residues," Langmuir, vol. 22, no. 11, pp. 49204922, 2006.

[98] G. Sun and Z. Guan, "Synthesis and investigation of coreshell dendritic nanoparticles with tunable thermosensitivity," Macromolecules, vol. 43, no. 23, pp. 9668-9673, 2010.

[99] Y. Haba, C. Kojima, A. Harada, and K. Kono, "Control of temperature-sensitive properties of poly(amidoamine) dendrimers using peripheral modification with various alkylamide groups," Macromolecules, vol. 39, no. 21, pp. 74517453, 2006.

[100] Y. Z. You, C. Y. Hong, C. Y. Pan, and P. H. Wang, "Synthesis of a dendritic core-shell nanostructure with a temperaturesensitive shell," Advanced Materials, vol. 16, no. 21, pp. 19531957, 2004.

[101] Y. Haba, A. Harada, T. Takagishi, and K. Kono, "Rendering poly(amidoamine) or poly(propylenimine) dendrimers temperature sensitive," Journal of the American Chemical Society, vol. 126, no. 40, pp. 12760-12761, 2004.

[102] J. Xu, S. Luo, W. Shi, and S. Liu, "Two-stage collapse of unimolecular micelles with double thermoresponsive coronas," Langmuir, vol. 22, no. 3, pp. 989-997, 2006.
[103] X. Z. Zhang, G. M. Sun, and C. C. Chu, "Temperature sensitive dendrite-shaped PNIPAAm/Dex-AI hybrid hydrogel particles: formulation and properties," European Polymer Journal, vol. 40, no. 9, pp. 2251-2257, 2004.

[104] J. T. Zhang, S. W. Huang, and R. X. Zhuo, "Temperaturesensitive polyamidoamine dendrimer/poly $(\mathrm{N}$ isopropylacrylamide) hydrogels with improved responsive properties," Macromolecular Bioscience, vol. 4, no. 6, pp. 575-578, 2004.

[105] W. Li, A. Zhang, K. Feldman, P. Walde, and A. D. Schlüter, "Thermoresponsive dendronized polymers," Macromolecules, vol. 41, no. 10, pp. 3659-3667, 2008.

[106] J. Chen, M. Liu, H. Liu, and L. Ma, "Synthesis, swelling and drug release behavior of poly $(\mathrm{N}, \mathrm{N}$-diethylacrylamide-co-Nhydroxymethyl acrylamide) hydrogel," Materials Science and Engineering C, vol. 29, no. 7, pp. 2116-2123, 2009.

[107] P. Qiao, Q. Niu, Z. Wang, and D. Cao, "Synthesis of thermosensitive micelles based on poly( $\mathrm{N}$-isopropylacrylamide) and poly(l-alanine) for controlled release of adriamycin," Chemical Engineering Journal, vol. 159, no. 1-3, pp. 257-263, 2010.

[108] K. Kono, T. Ozawa, T. Yoshida et al., "Highly temperaturesensitive liposomes based on a thermosensitive block copolymer for tumor-specific chemotherapy," Biomaterials, vol. 31, no. 27, pp. 7096-7105, 2010.

[109] I. Dimitrov, B. Trzebicka, A. H. E. Müller, A. Dworak, and C. B. Tsvetanov, "Thermosensitive water-soluble copolymers with doubly responsive reversibly interacting entities," Progress in Polymer Science, vol. 32, no. 11, pp. 1275-1343, 2007.

[110] Z. X. Zhang, X. Liu, F. J. Xu et al., "Pseudo-block copolymer based on star-shaped poly(N-isopropylacrylamide) with a $\beta$-cyclodextrin core and guest-bearing PEG: controlling thermoresponsivity through supramolecular self-assembly," Macromolecules, vol. 41, no. 16, pp. 5967-5970, 2008.

[111] I. W. Velthoen, J. V. Beek, P. J. Dijkstra, and J. Feijen, "Thermo-responsive hydrogels based on highly branched poly(ethylene glycol)-poly(L-lactide) copolymers," Reactive and Functional Polymers, vol. 71, no. 3, pp. 245-253, 2011.

[112] K. S. Soppimath, L. H. Liu, W. Y. Seow et al., "Multifunctional core/shell nanoparticles self-assembled from $\mathrm{pH}$ induced thermosensitive polymers for targeted intracellular anticancer drug delivery," Advanced Functional Materials, vol. 17, no. 3, pp. 355-362, 2007.

[113] J. Akimoto, M. Nakayama, K. Sakai, and T. Okano, "Thermally controlled intracellular uptake system of polymeric micelles possessing oly( $\mathrm{N}$-isopropylacrylamide)-based outer coronas," Molecular Pharmaceutics, vol. 7, no. 4, pp. 926-935, 2010.

[114] R. Rastogi, N. Gulati, R. K. Kotnala et al., "Evaluation of folate conjugated pegylated thermosensitive magnetic nanocomposites for tumor imaging and therapy," Colloids and Surfaces B, vol. 82, no. 1, pp. 160-167, 2011.

[115] K. Kono, S. Nakashima, D. Kokuryo et al., "Multi-functional liposomes having temperature-triggered release and magnetic resonance imaging for tumor-specific themotherapy," Biomaterials, vol. 32, no. 5, pp. 1387-1395, 2011. 

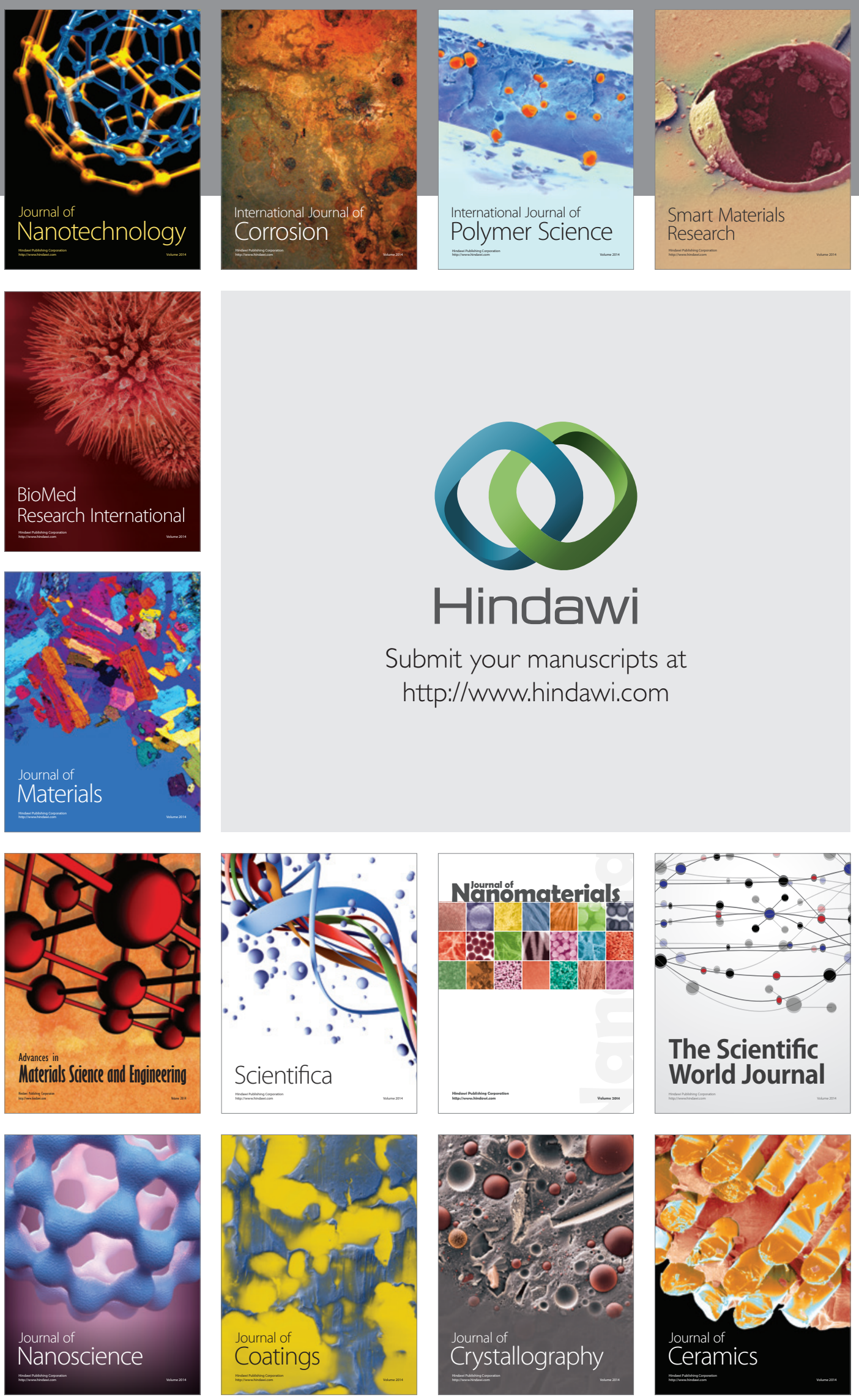

The Scientific World Journal

Submit your manuscripts at

http://www.hindawi.com

\section{World Journal}

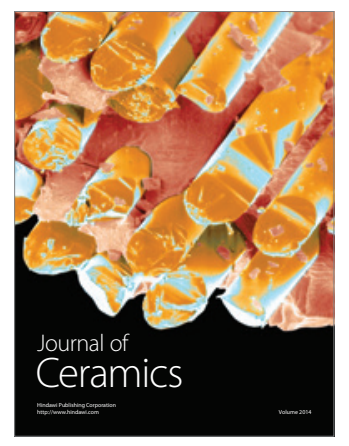

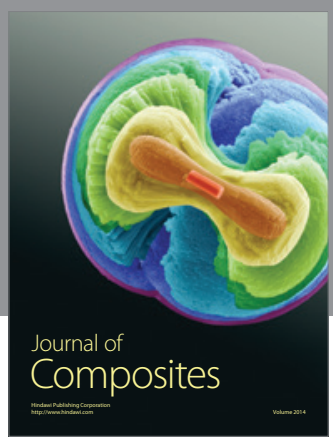
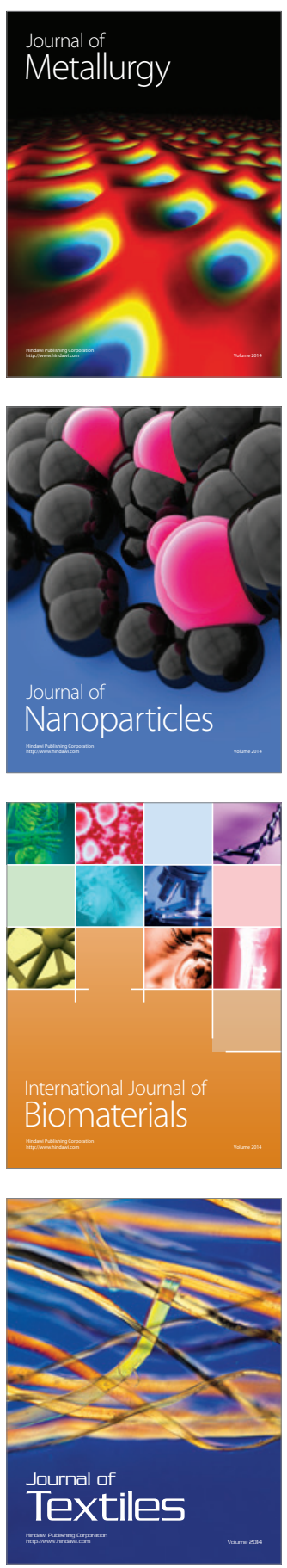